Article

\title{
Tapetal-Delayed Programmed Cell Death (PCD) and Oxidative Stress-Induced Male Sterility of Aegilops uniaristata Cytoplasm in Wheat
}

\author{
Zihan Liu, Xiaoyi Shi, Sha Li, Gan Hu, Lingli Zhang and Xiyue Song * \\ College of Agronomy, Northwest A\&F University, Yangling 712100, Shaanxi, China; \\ liuzihan@nwafu.edu.cn (Z.L.); shixiaoyiaza@163.com (X.S.); lisha2012@nwafu.edu.cn (S.L.); \\ huyunuo@163.com (G.H.); zhanglingli@nwafu.edu.cn (L.Z.) \\ * Correspondence: songxiyue@nwafu.edu.cn; Tel.: +86-29-8708-2845
}

Received: 24 May 2018; Accepted: 6 June 2018; Published: 8 June 2018

\begin{abstract}
Cytoplasmic male sterility (CMS) plays a crucial role in the utilization of hybrid vigor. Pollen development is often accompanied by oxidative metabolism responses and tapetal programmed cell death (PCD), and deficiency in these processes could lead to male sterility. Aegilops uniaristata cytoplasmic male sterility (Mu-CMS) wheat is a novel male-sterile line in wheat, which possess important potential in hybrid wheat breeding. However, its CMS mechanisms remain poorly understood. In our study, U87B1-706A, with the Aegilops uniaristata cytoplasm, and the maintainer line 706B were used to explore the abortive reason. Compared with 706B, histological analysis and PCD detection of the anther demonstrated that U87B1-706A appeared as delayed tapetal PCD as well as a disorganized organelle phenotype in the early uninucleate stage. Subsequently, a shrunken microspore and disordered exine structure were exhibited in the late uninucleate stage. While the activities of antioxidase increased markedly, the nonenzymatic antioxidant contents declined obviously following overacummulation of reactive oxygen species (ROS) during pollen development in U87B1-706A. Real-time quantitative PCR testified that the transcript levels of the superoxide dismutase $(S O D)$, catalase (CAT), and ascorbate peroxidase $(A P X)$ genes, encoding pivotal antioxidant enzymes, were up-regulated in early pollen development. Therefore, we deduce excess ROS as a signal may be related to the increased expression levels of enzyme genes, thereby breaking the antioxidative system balance, resulting in delayed tapetal PCD initiation, which finally led to pollen abortion and male sterility in U87B1-706A. These results provide evidence to further explore the mechanisms of abortive pollen in CMS wheat.
\end{abstract}

Keywords: cytoplasmic male sterility; gene expression; ROS metabolism; tapetal programmed cell death; wheat (Triticum aestivum L.)

\section{Introduction}

Hybrid wheat is considered as a promising approach to increase yield gains, yield stability and consequently, global productivity of wheat. Cytoplasmic male sterility (CMS) is a maternally inherited trait that results in the failure to produce functional pollen, which is widely employed for hybrid seed production to utilize heterosis in wheat [1]. Aegilops, as one of the most successful genera in wheat distant hybridization breeding, plays a critical role in cytoplasmic male-sterile wheat [2]. Tsunewaki et al. [3] demonstrated that Aegilops uniaristata (Mu-type) is one of the most valuable cytoplasms for the utilization of wheat male sterility lines in 40 wheat heterogeneous lines except for Ae. kostchyi. Besides, Ae. uniaristata has many excellent agronomic characteristics and increases resistance to wheat diseases, including stripe rust, leaf rust, stem rust and leaf spot, as well as tolerance 
to aluminum stress, and can also be used to improve the wheat grain protein content [4]. U87B1-706A, conferred by the cytoplasm from Ae. uniaristata, was developed from stable sterile lines by backcrossing with a maintainer over 20 times in Yangling, China. Our previous studies have shown that the line is easier to restore, having the higher germination rate of hybrid seeds as well as powdery mildew resistance compared with other cytoplasmic male sterility lines [5,6]. Therefore, the development of this line is of great value for the breeding and production of hybrid wheat, and it is also an ideal material for research of cytoplasm-nuclear interaction and pollen abortion. However, for economically important U87B1-706A, only agronomic traits have been studied and the abortive mechanism is still not clear and has not been investigated.

In plants, abnormal pollen development is a direct factor causing male sterility. Tapetum, as the innermost sporophytic layer, affects microsporogenesis by supplying proteins, lipids, and pigments, first through secretion and later through degradation. The development of normal pollen requires the proper timing of tapetal degradation, which occurs via developmentally regulated programmed cell death (PCD) [7]. Premature or delayed PCD by tapetal cells disorganizes the supply of the nutrients to microspores, thereby resulting in pollen abortion, which has been described in Actinidia deliciosa [8], Cactaceae [9], and Bromeliaceae [10]. Previous studies suggest this irregular tapetal PCD is tightly controlled by evolutionarily conserved transcriptional cascades [11-13]. Recently, the intracellular factors of the transcriptional networks regulating tapetal PCD have been identified, and the researchers indicated that the reactive oxygen species (ROS) act as important signal molecules in tapetal PCD in Solanaceae, Arabidopsis and rice [7,14]. However, these mechanisms leading to failed pollen development vary among examples and are rarely well understood. Moreover, few studies have considered the relationship between ROS and natural tapetal PCD in the anthers of CMS wheat, and it is unknown whether the mechanism exists in U87B1-706A wheat.

Mitochondria play a vital role to sustain cellular normal function, which includes initiation of PCD [15], response to oxidative stress signals [16], and synthesis of nucleic acids and proteins [17]. Primarily, the mitochondrion is also an important source of generating ROS, including hydrogen peroxide, superoxide anion radical, and hydroxyl radicals, and it may participate in oxidative damage [18]. If accumulated ROS are not removed from cells effectively and thoroughly, the cells will suffer from a wide variety of adverse effects including damaging nucleic acids, lipids and proteins. Considerable evidence indicates excess ROS accumulation could be associated with the induction of antioxidant genes, thereby causing more efficient enzyme stimulation and protection [19,20]. Plant cells are provided with a high-efficiency antioxidant system consisting of antioxidant enzymes (superoxide dismutase (SOD), catalase (CAT), peroxidase (POD), ascorbate peroxidase (APX), and glutathione peroxidase (GPX)) and non-enzymatic antioxidants (ascorbic acid ASA and glutathione GSH). The alleviation of biotic and abiotic stress in plants transformed with genes, related to antioxidative enzymes, strongly suggests the significantly important role of these enzymes and the genes encoding these enzymes in conferring tolerance [21]. Despite these facts, previous research suggested CMS is linked to the imbalance between production and scavenging of ROS [22]; however, the relationships between dynamic ROS, the antioxidant system, the transcript levels of related genes, and tapetal PCD for CMS remain unclear, especially in wheat.

To deeply explore the abortive mechanisms of the Mu-type CMS in wheat (Triticum aestivum L.), in the present study, we investigated the characteristics of U87B1-706A with Ae. uniaristata cytoplasm in cytological, physiological, and molecular analyses. In detail, we analyzed morphological and tapetal changes during different developmental stages by histological analysis and further detected the PCD though the terminal deoxynucleotidyl transferase-mediated 2'-Deoxyuridine 5'-Triphosphate nick-end labeling (TUNEL) assay and DNA laddering analysis, where we identified the period of abortion based on iodine-potassium iodide ( $\left.\mathrm{I}_{2}-\mathrm{KI}\right)$ staining, scanning electron microscopy (SEM) observations, and 4',6-diamidino-2-phenylindole (DAPI) staining. Additionally, we determined physiological indices and validated the expression levels of the $S O D, C A T$, and $A P X$ genes, encoding important antioxidant enzymes by quantitative real-time PCR (qRT-PCR). The results of this study will provide new insights 
into abortive metabolism in Mu-type CMS wheat, as well as a theoretical basis for the breeding and application of excellent sterile wheat lines.

\section{Results}

\subsection{Abortive Morphological Features in U87B1-706A}

In order to gain the abortive morphological features of U87B1-706A, the anthers from five different developmental stages were analyzed in detail. Similar to the anthers of 706B, U87B1-706A appeared to have normal stamens and pistils at the tetrad stage and the early uninucleate stage (Figure 1A,B,F,G). Nevertheless, at the late uninucleate stage and the binucleate stage, compared with the maintainer, the anthers of the sterile line were smaller and more greenish (Figure $1 \mathrm{C}, \mathrm{D}, \mathrm{H}, \mathrm{I}$ ). Correspondingly, for the anthers of the trinucleate stage, we further used SEM to observe the surfaces of the inner and outer epidermis of anthers. Unlike the fertile plants, the anthers of U87B1-706A were not dehiscent in the trinucleate stage, and no mature pollen grains were released (Figures 1E,J and $2 \mathrm{~A}, \mathrm{~F}, \mathrm{~J}, \mathrm{O})$. The outer epidermal cells of fertile plants anthers were arranged neatly, whereas U87B1-706A displayed shrunken and irregular shapes (Figure 2B,C,K,L). Moreover, compared with 706B, the inner epidermal Ubisch bodies of U87B1-706A were accumulated fewer and more sparsely distributed (Figure 2D,E,M,N and Supplementary Figure S1). Based on observations of microspores at the trinucleate stage, the microspores of 706B were plump and rounded with a gymnotremoid germinal aperture; by contrast, the microspores of U87B1-706A were extremely wizened and atrophied, with a malformed germinal aperture (Figure $2 \mathrm{H}, \mathrm{I}, \mathrm{Q}, \mathrm{R}$ ). According to $\mathrm{I}_{2}-\mathrm{KI}$ staining and statistical analysis of abortion types, the results showed $34.4 \%$ mature pollen grains were typical abortion, which presented an irregular shape and a lack of dye uptake. However, the $65.6 \%$ mature microspores were round but the staining was not sufficient, which reflected the trait of stainable abortion. Therefore, unlike $706 \mathrm{~B}$, the pollen abortion types of U87B1-706A had typical and stainable abortion $[23,24]$, and the plants were 100\% pollen sterile (Figure 2G,P and Supplementary Figure S2). These results demonstrate that nucleo-cytoplasmic interactions have a major influence on the development of the pollen grain and anther.
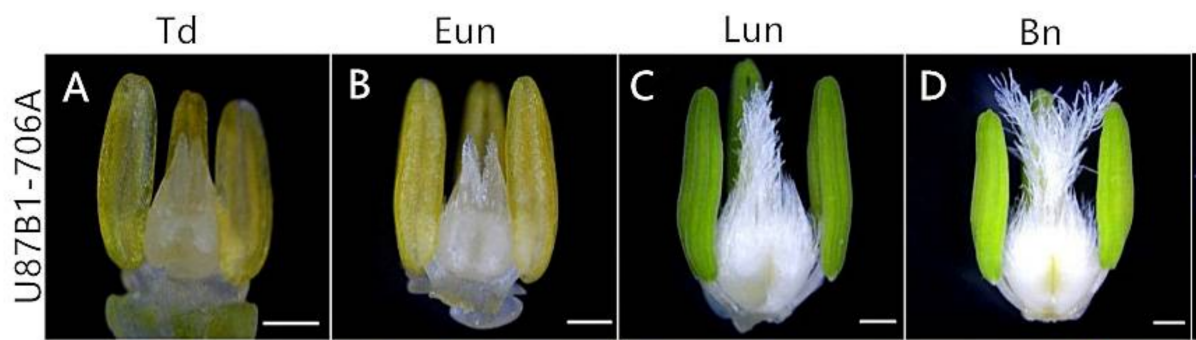

$\mathrm{Tn}$
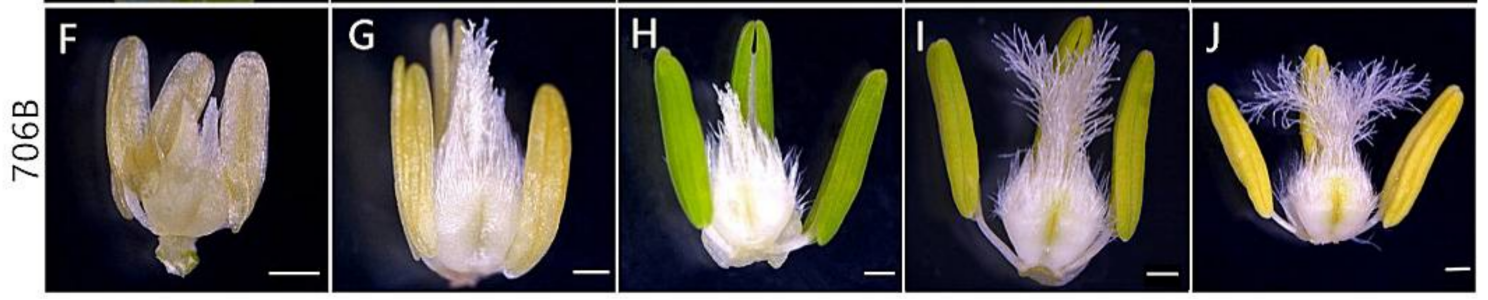

Figure 1. Comparisons of the anther phenotype in U87B1-706A (A-E) and 706B (F-J). (A,F) Td, tetrad stage; $(\mathbf{B}, \mathbf{G})$ Eun, early uninucleate stage; $(\mathbf{C}, \mathbf{H})$ Lun, late uninucleate stage; $(\mathbf{D}, \mathbf{I}) \mathrm{Bn}$, binucleate stage; and $(\mathbf{E}, \mathbf{J}) \mathrm{Tn}$, trinucleate stage. Scale bars are $500 \mu \mathrm{m}$ in $(\mathbf{A}-\mathbf{J})$. 


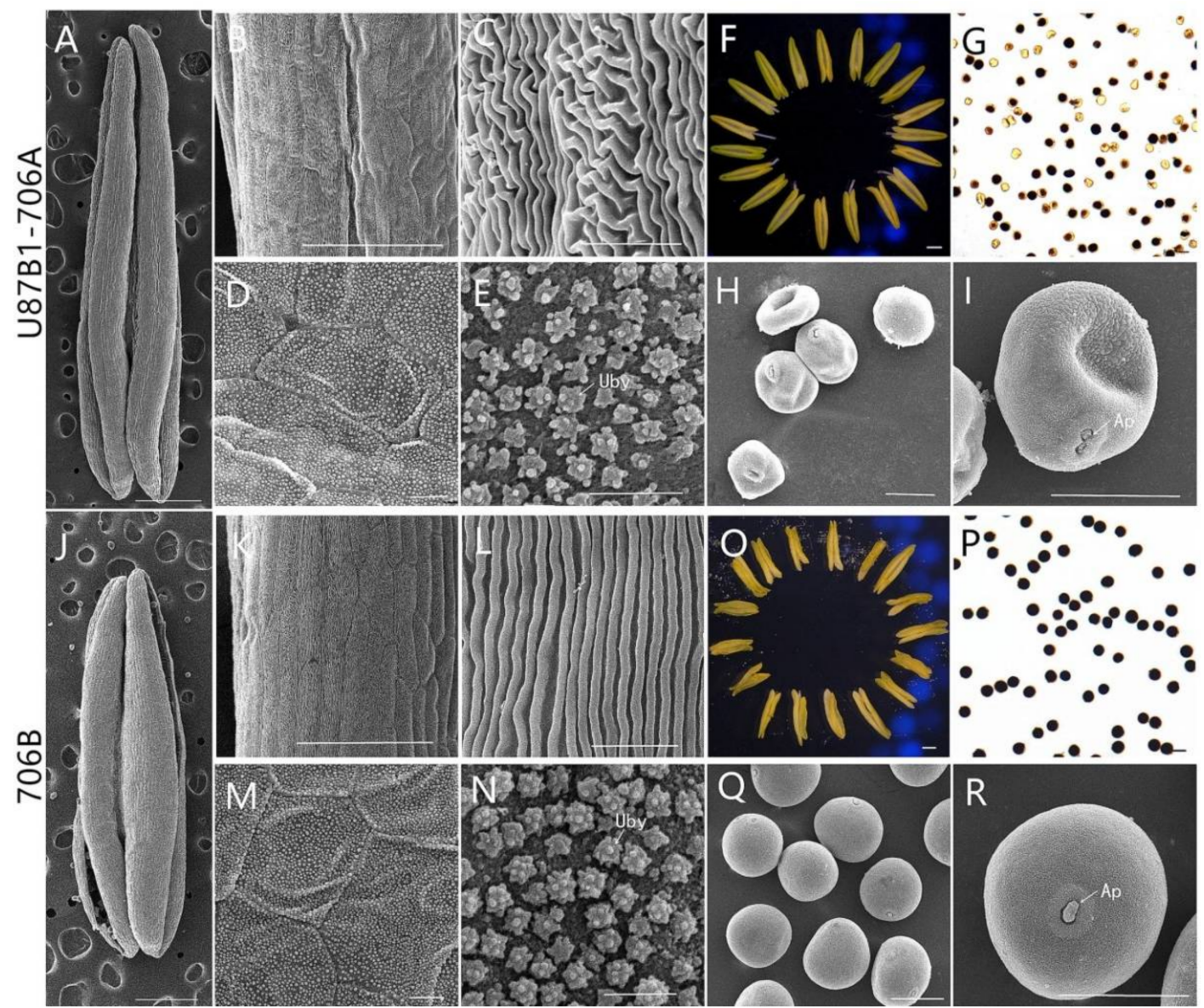

Figure 2. Comparison of scanning electron micrograph observations, $\mathrm{I}_{2}-\mathrm{KI}$ staining, and anther morphology in U87B1-706A (A-I) and 706B (J-R) at the trinucleate (Tn) stage. (A,F,J,O): anthers; (B,C,K,L): outer epidermal cells; $(\mathbf{D}, \mathbf{E}, \mathbf{M}, \mathbf{N})$ : inner epidermal cells; $(\mathbf{G}, \mathbf{P})$ : microspores by $\mathrm{I}_{2}-\mathrm{KI}$ staining; $(\mathbf{H}, \mathbf{I}, \mathbf{Q}, \mathbf{R})$ : microspores; Uby, Ubisch bodies; Ap, germination aperture. Scale bars are $1 \mathrm{~mm}$ in $(\mathbf{A}, \mathbf{F}, \mathbf{J}, \mathbf{Q})$; $100 \mu \mathrm{m}$ in $(\mathbf{B}, \mathbf{K}) ; 50 \mu \mathrm{m}$ in $(\mathbf{G}-\mathbf{I}, \mathbf{P}-\mathbf{R}) ; 10 \mu \mathrm{m}$ in $(\mathbf{C}-\mathbf{E}, \mathbf{L}-\mathbf{N})$.

\subsection{Tapetal Development in Anthers}

To further explore the reason of pollen and anther abortion in U87B1-706A, we first conducted observations of the tapetum during the different developmental stages based on paraffin and semi-thin transverse sections and CellSens Entry software. At the tetrad stage and early uninucleate stage, light microscopy observations revealed that the anther locules were composed of four layers, from inside to outside, which were the innermost tapetum, the middle layer, the endothecium, and the epidermis. In addition, there were no obvious differences at the tetrad stage and early uninucleate stage in the tapetal cells between 706B and U87B1-706A, which could not be degraded (Figure 3A,B,F,G, Supplementary Figures S3A,B,F,G and S4). However, during the later uninucleate stage, the areas of the tapetal cells in U87B1-706A were unconventionally larger than those in 706B, and they occupied the majority of the anther locule instead of degenerating to secrete nutrients for microspore formation (Figure 3C,H, Supplementary Figures S3C,H and S4). At the binucleate stage, the tapetum shrank and condensed obviously and was reduced to a very thin layer (Figure 3D,I and Supplementary Figure S3D,I). Up to the trinucleate stage, the outlines of the tapetal cell in 706B were completely invisible and the anther wall layers were thinner, thereby contributing to the release of mature pollen grains by anther dehiscence to pollinate female gametophytes. In addition, the epidermis and endothecium of sterile and fertile anthers in the trinucleate stage were thicker compared with the binucleate stage (Figure 3J and Supplementary Figure S3J). However, the anther wall of U87B1-706A 
was not fractured at the trinucleate stage, and the invasion of the cell mass could cause the abortion of microspores (Figure 3E and Supplementary Figure S3E). Therefore, we deduced that delayed tapetum dysfunction may result in the abortion of U87B1-706A.

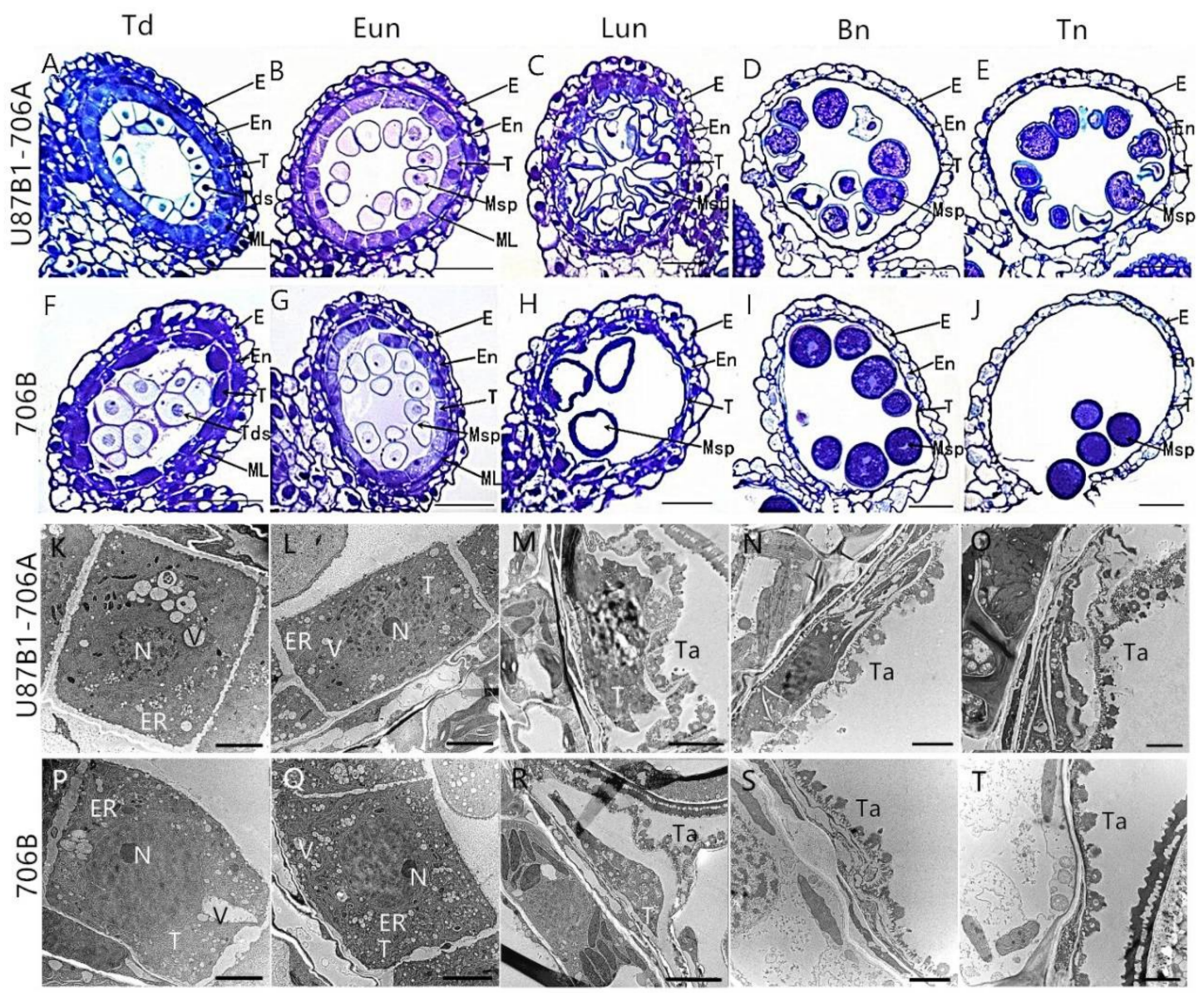

Figure 3. Comparisons of the anther tapetum (A-J) and ultrastructure (K-T) in U87B1-706A (A-E,K-O) and $706 \mathrm{~B}(\mathbf{F}-\mathbf{J}, \mathbf{P}-\mathbf{T})$ during different developmental stages. (A,F,K,P) Td, tetrad stage; $(\mathbf{B}, \mathbf{G}, \mathbf{L}, \mathbf{Q})$ Eun, early uninucleate stage; $(\mathbf{C}, \mathbf{H}, \mathbf{M}, \mathbf{R})$ Lun, late uninucleate stage; $(\mathbf{D}, \mathbf{I}, \mathbf{N}, \mathbf{S}) \mathrm{Bn}$, binucleate stage; and $(\mathbf{E}, \mathbf{J}, \mathbf{O}, \mathbf{T}) \mathrm{Tn}$, trinucleate stage. E, epidermis; En, endothecium; ER, endoplasmic reticulum; ML, middle layer; Msp, microspores; N, nucleus; T, tapetum; Ta: tapetosome; Tds, tetrads; V: vacuole. Scale bars are $50 \mu \mathrm{m}$ in $(\mathbf{A}-\mathbf{J})$ and $2 \mu \mathrm{m}$ in $(\mathbf{K}-\mathbf{T})$.

To verify the inference of the paraffin and semithin sections and further observe the tapetal organelles, transmission electron microscopy (TEM) was implemented during all of the developmental stages. Consistent with the results of semi-thin sections, the results of the ultrathin section confirmed the abnormal degradation of the tapetum also occurs in the later uninucleate stage. The tapetal cells were still quite intact at the tetrad and early uninucleate stages in U87B1-706A, whereas nuclear chromatins were more blurred and the nuclear membranes were less obvious than those in 706B. The tapetal cells exhibited a spongy feature because of the distribution of numerous vesicles and secretory vacuoles, and endoplasmic reticula expanded continually in the anther locules of U87B1-706A (Figure 3K,L,P,Q). From the later uninucleate stage to trinucleate stage, compared with 706B, tapetosomes of U87B1-706A were comparatively scattered and displayed distinct abnormality in tapetal cells, and the organelles were also indistinct (Figure $3 \mathrm{M}-\mathrm{O}, \mathrm{R}-\mathrm{T}$ ). These observations indicate that the abortive reason is probably anomalous changes of organelles in tapetum, thereby causing the delayed tapetal degradation. 


\subsection{Tapetal PCD Detection in Anthers}

In order to further characterize the tapetal PCD, we analyzed the cleavage of nuclear DNA using the TUNEL assay in U87B1-706A and 706B during different developmental stages. At the tetrad stage, there was no TUNEL fluorescence signal in tapetal cells of U87B1-706A and 706B (Figure 4A,F). At the early uninucleate stage, green TUNEL-positive signals were found in 706B tapetum, thereby indicating that the PCD of the tapetum was present in this stage, while the TUNEL PCD signals were not detected in the tapetum of U87B1-706A (Figure 4B,G and Supplementary Figure S5). Subsequently, until the later uninucleate stage, a weaker TUNEL-positive signal was produced in U87B1-706A tapetum. Compared with U87B1-706A, stronger TUNEL-positive signals occurred in the degenerating tapetum in 706B, which explained the obvious accumulation of DNA cleavage in this stage (Figure $4 \mathrm{C}, \mathrm{H}$ and Supplementary Figure S5). From the binucleate stage to the trinucleate stage, the intense TUNEL-positive signals were also observed in the epidermis and the endothecium cells in U87B1-706A and 706B (Figure 4D,E,I,J). In a word, these observations verified that the initiation of tapetal cell PCD was delayed in U87B1-706A.
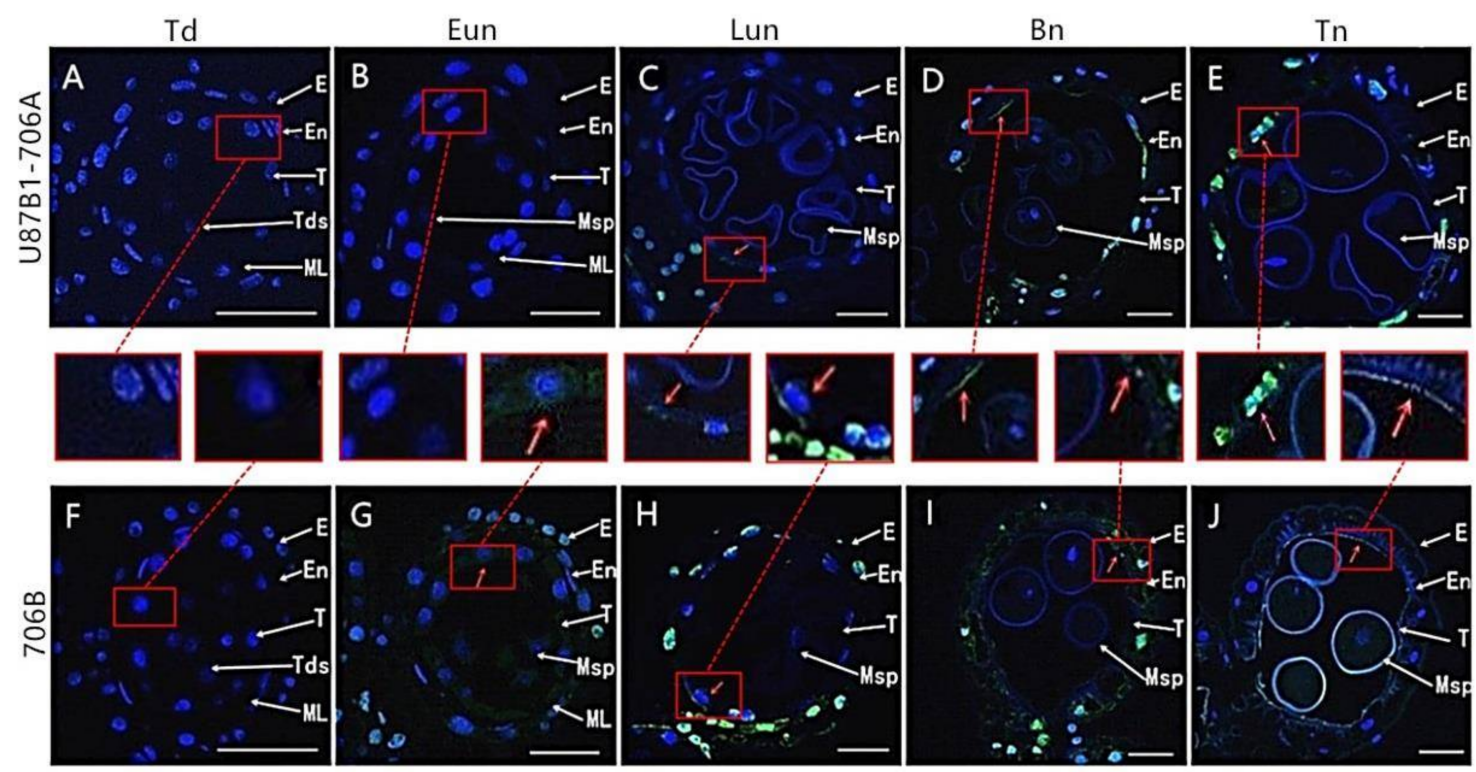

Figure 4. TUNEL assays to detect anther tapetum PCD in U87B1-706A (A-E) and 706B (F-J) during different developmental stages. (A,F) Td, tetrad stage; $(\mathbf{B}, \mathbf{G})$ Eun, early uninucleate stage; $(\mathbf{C}, \mathbf{H})$ Lun, late uninucleate stage; (D,I) Bn, binucleate stage; and (E,J) Tn, trinucleate stage. E, epidermis; En, endothecium; ML, middle layer; T, tapetum; Tds, tetrads; Msp, microspores. The green fluorescence denoted by the red arrows indicates nuclei with TUNEL-positive staining. To make green fluorescence visible, the red square shows enlarged example. Scale bars are $50 \mu \mathrm{m}$ in (A-J).

For both U87B1-706A and 706B, DNA damage levels were determined during different developmental stages in the anthers by DNA laddering to better determine the TUNEL assay result. Similar to the TUNEL PCD detection, a significant DNA fragmentation in 706B first appeared at the early uninucleate stage, whereas the DNA fragmentation of U87B1-706A formed ladders with bands at the later uninucleate stage (Supplementary Figure S6). The results of the DNA ladder assays indicate that the anther tapetum exhibited typical PCD characteristics, where U87B1-706A exhibited deferred PCD in the tapetum. We also found that the molecular features of PCD were observed earlier than the cytological phenotype in U87B1-706A and 706B. 


\subsection{Cytological Characteristics of Microspores}

In plants, the tapetum can provide the nutrients for the normal development of microspores though timely tapetal PCD [25]. Thus, the DAPI and acetocarmine staining were carried out to investigate pollen development to further clarify whether the abnormal pollen development was associated with abnormal tapetal PCD in U87B1-706A. At the tetrad stage and the early uninucleate stage, no obvious variations in microspore development of U87B1-706A were observed compared with 706B: the microspores were released from the tetrads and experienced normal development, where the nuclei were located at the center of the cell (Figure 5A,B,F,G and Supplementary Figure S7). At the late uninucleate stage, the microspores of 706B and U87B1-706A had a huge vacuole, where the nuclei were displaced to the opposite side of the germination aperture. However, unlike 706B, the microspores were severely corrugated in U87B1-706A in the late uninucleate stage (Figure 5C,H and Supplementary Figure S7C,H). Up to the binucleate stage, the microspores of 706B gradually enlarged, thereby forming rounded and compact vegetative and sperm nuclei in 706B. In contrast to $706 \mathrm{~B}$, the vegetative and sperm nuclei were slightly bigger in U87B1-706A than in 706B, and some of the vegetative nuclei were not clear (Figure 5D,I and Supplementary Figure S7D,I). At the trinucleate stage, the sperm nuclei became round in U87B1-706A instead of the normal spindle shape (Figure 5E,J and Supplementary Figure S7E,J). Therefore, we suggest that the delayed tapetal PCD of U87B1-706A led to abnormal pollen development in the late uninucleate stage due to not contributing to nutrients in time for the development of microspores.
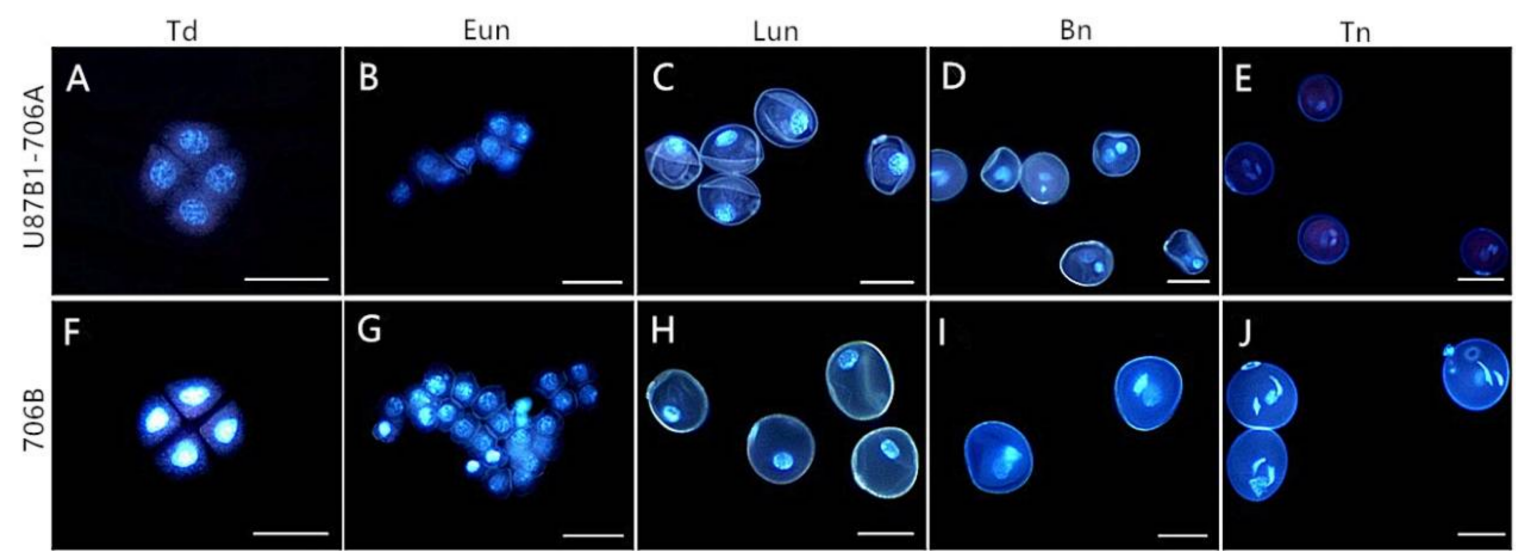

Figure 5. DAPI staining of microspores in U87B1-706A (A-E) and 706B (F-J). (A,F) Td, tetrad stage; $(B, G)$ Eun, early uninucleate stage; $(\mathbf{C}, \mathbf{H})$ Lun, late uninucleate stage; $(\mathbf{D}, \mathbf{I}) \mathrm{Bn}$, binucleate stage; and $(\mathbf{E}, \mathbf{J}) \mathrm{Tn}$, trinucleate stage. Scale bars are $50 \mu \mathrm{m}$ in $(\mathbf{A}-\mathbf{J})$.

During the pollen development process, proper tapetal PCD also could provide enough sporopollenin to maintain normal pollen wall development [26]. Therefore, we used TEM to observe the ultrastructure of microspores to further confirm whether the abnormal pollen wall was synchronized with tapetal PCD delay in U87B1-706A. During the tetrad stage, the pollen wall is composed of plasma membrane, primexine and callose. Up to the early uninucleate stage, the sexine was formed with the continuous accumulation of sporopollenins (deposit materials). In these two stages, there were no distinct differences between U87B1-706A and 706B in the pollen wall (Figure 6A,B,F,G,K,L,P,Q). However, unlike 706B, the abnormal accumulation of sporopollenin in U87B1-706A resulted in the inability to form normal sexine in the subsequent process of pollen development. Disordered and incomplete primary exine and sexine structures appeared on U87B1-706A microspore surface (Figure 6C-E,H-J,M-O,R-T). These observations indicate that incompatible nucleus and mitochondria might trigger delayed PCD in the tapetum, thereby hindering the secretion of sporopollenin during pollen development, which causes defective pollen exine, and results in male sterility of U87B1-706A. 

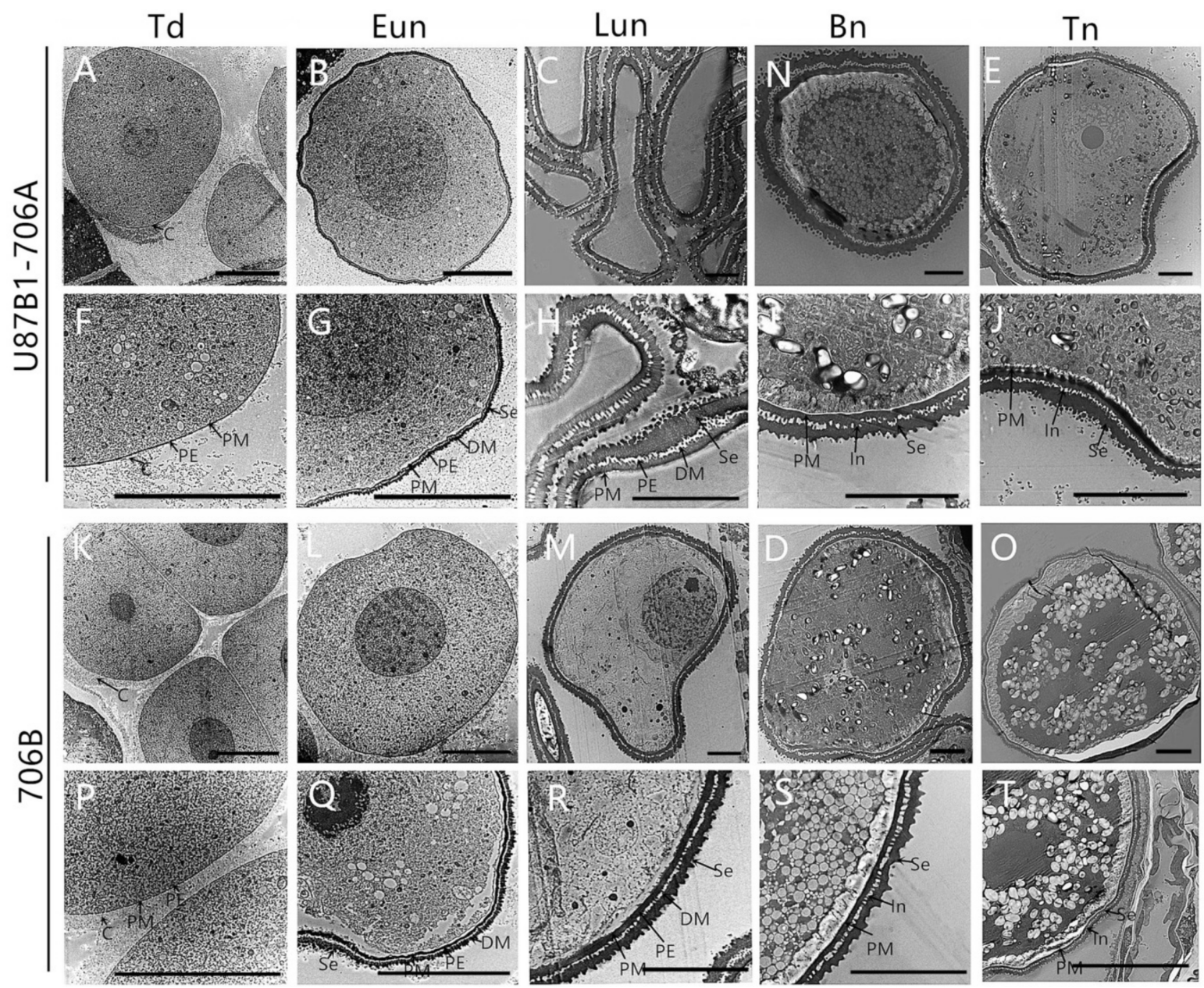

Figure 6. Transmission electron micrographs of the microspores in U87B1-706A (A-J) and 706B (K-T). $(\mathbf{A}, \mathbf{F}, \mathbf{K}, \mathbf{P}) \mathrm{Td}$, tetrad stage; $(\mathbf{B}, \mathbf{G}, \mathbf{L}, \mathbf{Q})$ Eun, early uninucleate stage; $(\mathbf{C}, \mathbf{H}, \mathbf{M}, \mathbf{R})$ Lun, late uninucleate stage; $(\mathbf{D}, \mathbf{I}, \mathbf{N}, \mathbf{S}) \mathrm{Bn}$, binucleate stage; and $(\mathbf{E}, \mathbf{J}, \mathbf{O}, \mathbf{T}) \mathrm{Tn}$, trinucleate stage. C, callose; PE, primexine; Se, sexine; DM, deposit materials; PM, plasma membrane; In, intine. Scale bars are $3 \mu \mathrm{m}$ in (A-T).

\section{5. $\mathrm{O}_{2}{ }^{-}$Generation Rate and Contents of $\mathrm{H}_{2} \mathrm{O}_{2}$ and $\mathrm{MDA}$}

To further explore the reason for abnormal anther tapetal PCD and microspores, we examined the $\mathrm{O}_{2}{ }^{-}, \mathrm{H}_{2} \mathrm{O}_{2}$ and malondialdehyde (MDA) contents during the different developmental stages in the anthers of U87B1-706A and 706B. The $\mathrm{O}_{2}{ }^{-}$and $\mathrm{H}_{2} \mathrm{O}_{2}$ contents were continuously increased in U87B1-706A with peak values in the late uninucleate stage, which were significantly higher than in 706B during the early development of pollen (Figure 7A,B). The later stages of pollen development were accompanied by the extremely high MDA contents in U87B1-706A than in 706B, whereas the MDA contents were low in the tetrad stage and early uninucleate stage (Figure $7 \mathrm{C}$ ). Thus, we suggest that the excessive accumulation of ROS in U87B1-706A during the early anther developmental stages could act as a signal to trigger the anomalous tapetal PCD. 

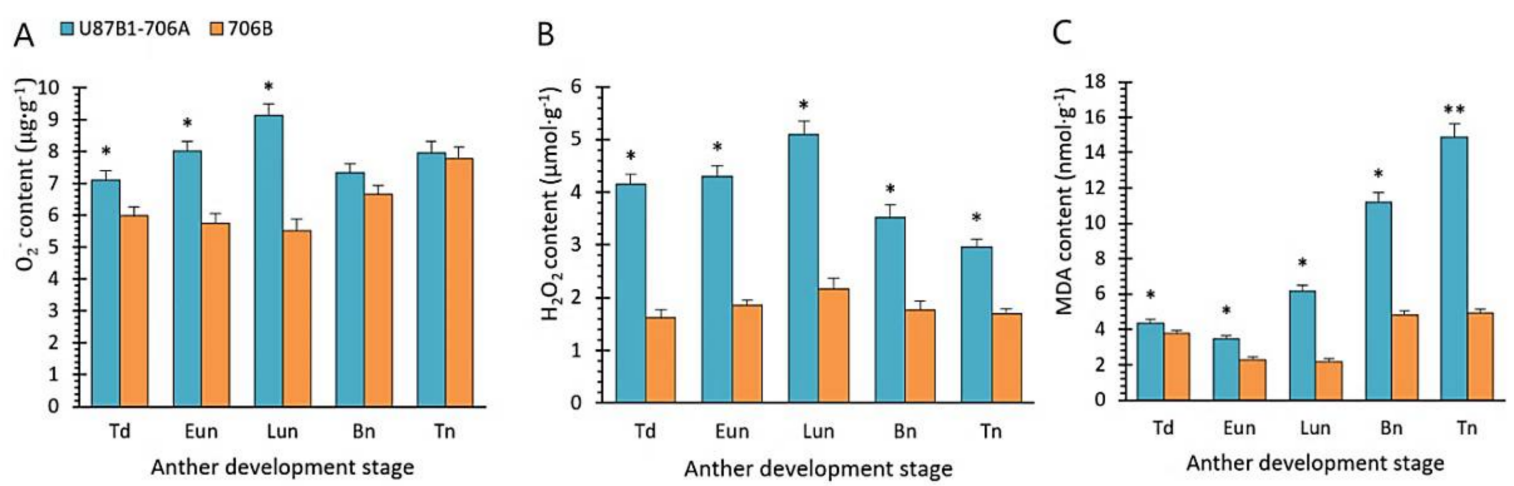

Figure 7. Accumulation of $\mathrm{O}_{2}{ }^{-}, \mathrm{H}_{2} \mathrm{O}_{2}$, and MDA in the anthers of U87B1-706A and 706B during various developmental stages. $\mathrm{Td}$, tetrad stage; Eun, early uninucleate stage; Lun, late uninucleate stage; $\mathrm{Bn}$, binucleate stage; and $\mathrm{Tn}$, trinucleate stage. (A) $\mathrm{O}_{2}{ }^{-}$contents; (B) $\mathrm{H}_{2} \mathrm{O}_{2}$ contents; (C) MDA contents. Students' $t$ test ${ }^{*} p<0.05,{ }^{* *} p<0.01$. Each value represents the mean $\pm \operatorname{SD}(n=3)$.

\subsection{Activities of Antioxidant Enzymes and Nonenzymatic Antioxidants}

As compared to 706B, there was a decline in the ASA and GSH activity levels in U87B1-706A during the entire period of pollen development, where the differences between U87B1-706A and 706B were significant. In addition, contrary to 706B, the ASA and GSH activity levels had a rapid decline until the late uninucleate stage in U87B1-706A, before an increase in the later stages of pollen development (Figure 8A,B). Furthermore, the activities of antioxidant enzymes, i.e., SOD, CAT, POD, APX, and GPX, were determined. The SOD and POD activities were always higher in U87B1-706A than those in 706B during the whole course of pollen development, while the CAT, APX contents were higher than 706B only in the tetrad stage and the early uninucleate stage. Likewise, a sharp increase in the GPX contents occurred in U87B1-706A during the tetrad stage; differences were significant between 706B and U87B1-706A $(p<0.01)$ (Figure $8 \mathrm{C}-\mathrm{G})$. According to these outcomes, it is possible that the nonenzymatic antioxidants may have been weaker in U87B1-706A than 706B, thereby causing excess accumulation of ROS, thus leading to the up-regulation of the activities of antioxidant enzymes, finally disrupting the balance of antioxidant system and endogenous hormones.
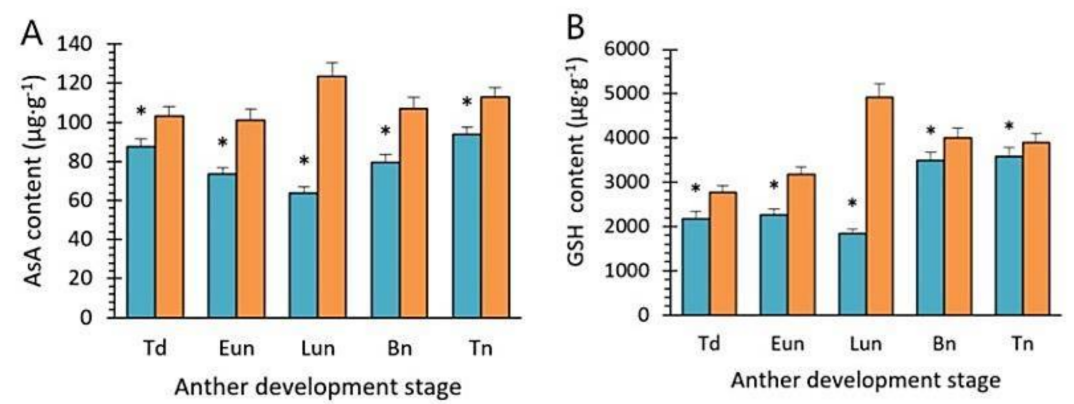

ロU87B1-706A $\square 706 B$
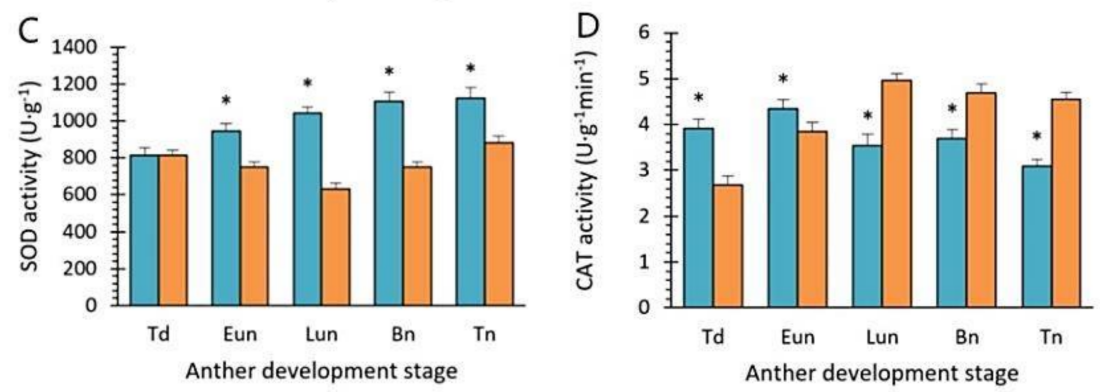

口U87B1-706A घ706B

Figure 8. Cont. 

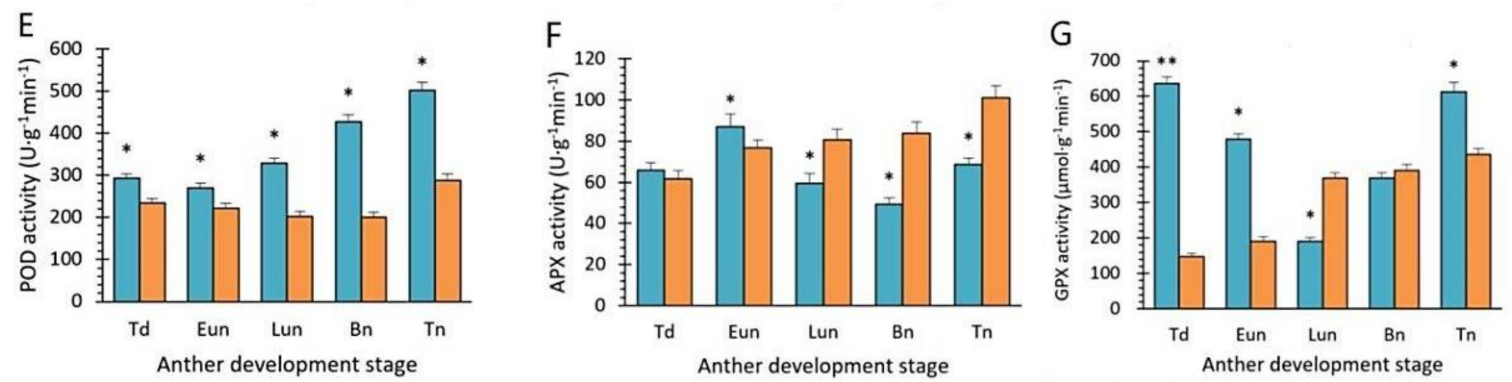

Figure 8. Nonenzymatic antioxidant contents (A,B) and activities of antioxidant enzymes (C-G) in anthers from U87B1-706A and 706B during different developmental stages. Td, tetrad stage; Eun, early uninucleate stage; Lun, late uninucleate stage; Bn, binucleate stage; and Tn, trinucleate stage. (A) AsA contents; (B) GSH contents; (C) SOD activity; (D) CAT activity; (E) POD activity; (F) APX activity; (G) GPX activity. Students' $t$ test ${ }^{*} p<0.05,{ }^{* *} p<0.01$. Each value represents the mean $\pm \operatorname{SD}(n=3)$.

\subsection{Expression Levels of Antioxidant Enzyme Genes}

The expression levels of $S O D, C A T$ and $A P X$ genes encoding important antioxidant enzymes were determined in U87B1-706A and 706B during the different developmental stages. In addition, the correlations between the enzyme activities and genes expression levels were analyzed through the tendency chart and SPSS software. The dynamics of the SOD gene expression levels were similar between U87B1-706A and 706B, but higher than that of 706B during all anther developmental stages (Figure 9A and Supplementary Figure S8). Additionally, the correlative assay showed that SOD enzyme activities and SOD gene expression levels were extremely significantly correlated in U87B1-706A (Supplementary Figure S9). The CAT gene and APX expression levels continuously decreased in U87B1-706A, whereas those of 706B gradually increased throughout anther development. Moreover, there was a significant difference between U87B1-706A and 706B in the CAT gene expression level at the tetrad stage (Figure 9B,C and Supplementary Figure S8). The results of correlations indicated that all of the enzyme activities and the related gene expression levels were positively correlated (Supplementary Figure S9). From these results, it can be concluded that the disordered dynamics of ROS, the expression of related enzymes, and the antioxidant system were consistent with the abnormal tapetal PCD in the anther of U87B1-706A.
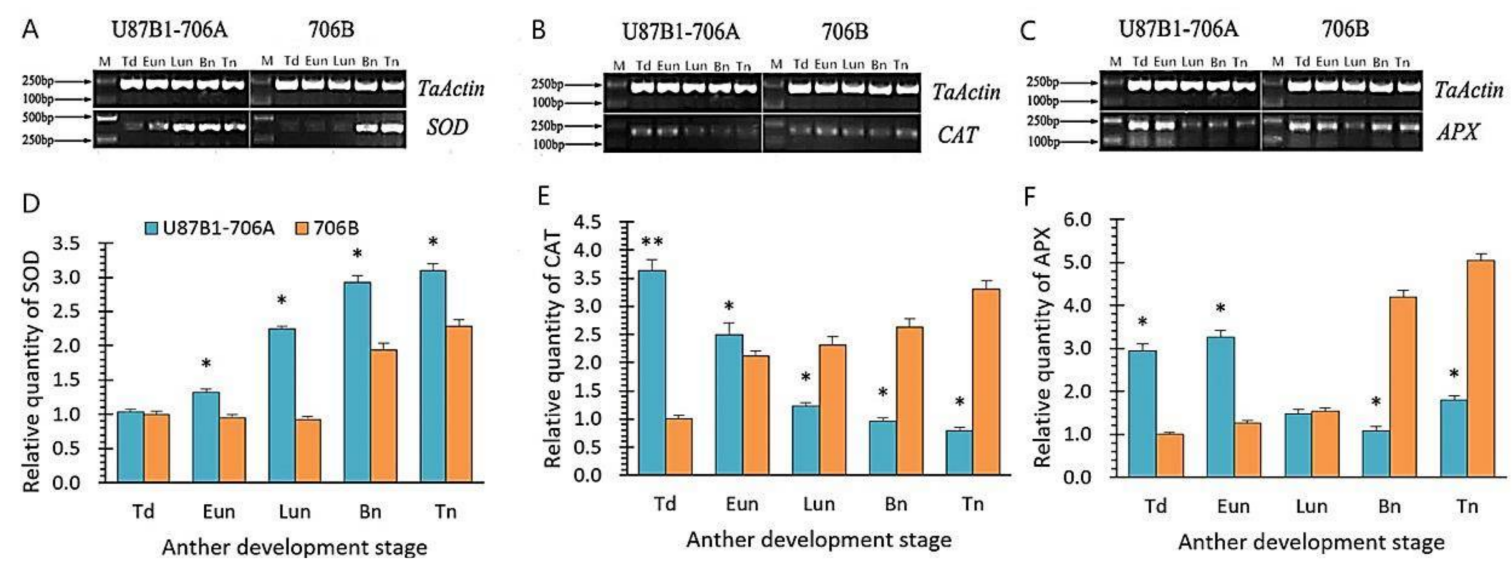

Figure 9. Results of gene expression for $S O D(\mathbf{A}, \mathbf{D}), C A T(\mathbf{B}, \mathbf{E})$, and $A P X(\mathbf{C}, \mathbf{F})$ in anthers from U87B1-706A and 706B during different developmental stages. Td, tetrad stage; Eun, early uninucleate stage; Lun, late uninucleate stage; Bn, binucleate stage; and Tn, trinucleate stage. M, Marker D2000. Students' $t$ test ${ }^{*} p<0.05,{ }^{* *} p<0.01$. Each value represents the mean $\pm \operatorname{SD}(n=3)$. 


\section{Discussion}

\subsection{The Critical Period of Abortion in Mu Type-CMS}

In angiosperms, normal release of pollen from the anther and proper development are essential for successful reproduction. However, many studies have shown that different plants vary in terms of their abortion periods and characteristics. Previous research suggests that $4 \%$ of abortions occur in the early stages of meiosis, $57 \%$ during the tetrad stage, and 39\% in the microspore developmental stage in monocotyledonous plants. In dicotyledonous plants, $27 \%$ of abortions occur in early meiosis, $58 \%$ in the tetrad stage, and $15 \%$ in the microspore developmental stage [27]. According to our light and electron microscopy analyses of the cytological study, we discovered that the microspores of U87B1-706A first showed abortive characteristics at the late uninucleate stage, where they eventually were completely aborted by the trinucleate stage. Tapetum degradation is considered as a direct factor of pollen abortion in male sterility $[28,29]$. At the same time, compared with the control plants $706 \mathrm{~B}$, there was an obviously delayed degradation of tapetal cell and abnormalities of organelles of U87B1-706A at the late uninucleate stage. Generally speaking, morphological features of the degradation of the tapetum are identified as results of PCD during the development of the anther [9,30]. When PCD occurs in the tapetum, normal DNA could degrade into nuclear DNA fragmentation to form nucleosomes of more than $140 \mathrm{bp}$, and subsequently abnormal cytological morphology will be visible [31,32]. Furthermore, in this study, the TUNEL and DNA laddering were performed to precisely explore the accurate stage of pollen abortion, and the results indicated that the TUNEL PCD signals of 706B was first present in the early uninucleate stage, while there were no TUNEL PCD signals in U87B1-706A. Therefore, we deduce the critical period of abortion of U87B1-706A is probably at the early uninucleate stage owing to the delayed initiation of tapetal PCD.

\subsection{Tapetal PCD and Pollen Abortion in Mu Type-CMS}

In the present study, based on our morphological observation, four anther cell wall layers appeared, which successively were the epidermis, the endothecium, the middle layer, and the tapetum from exterior to interior. The tapetum is a very special cell layer between the anther wall and microspores, which is located in the innermost of anther wall and secretes nutrients, sporopollenin precursors, and enzymes for pollen development [33]. Tapetal degeneration is a very strict process that will lead to pollen abortion if it is not performed in an orderly and synchronized manner [34]. In this study, our cytological semi-thin section combined with the ultrathin section analyses indicated although the tapetal phenotype of U87B1-706A appeared normal based on semi-thin sections at the early uninucleate stage, the tapetal organelles were initially abnormal and presented an irregular appearance in this stage, which demonstrates that organelle disorder occurred first in the abnormal degradation of the tapetum. In general, tapetal degradation is regarded as the result of PCD, which is resulted of DNA fragmentation [35]. Similarly, TUNEL and DNA laddering analysis provided direct evidence that the PCD of tapetal cells was also detected in 706B and U87B1-706A, and further demonstrated that U87B1-706A underwent deferred PCD of the tapetal cells, thereby causing the collapse of microspores and male sterility due to a lack of essential materials and signals for proper microspore development. How does the abnormal PCD of the tapetum cause pollen abortion? Previously, researchers suggested that tapetal PCD could provide the completion of the extracellular sculpting of the pollen and promote metabolites, pollen wall synthesis and pollen deposition [7]. Therefore, differences in biosynthesis and exogenous inputs in sterile plants disrupted energy metabolism, thus accelerating pollen abortion [26]. The pollen exine, as the outermost layer of the pollen wall, is composed mostly of sporopollenin, which is secreted from the tapetum via PCD [36]. In U87B1-706A, the delayed tapetal PCD could lead to incomplete sporopollenin synthesis, thereby causing irregular microspore morphology and male sterility. 


\subsection{ROS and Antioxidant Defense System in Mu Type-CMS}

Plant mitochondria are a main cellular source of ROS throughout the entire respiratory process, and are one of the major targets of ROS under oxidative stress, which can disrupt mitochondrial normal function due to excessive ROS production [37]. In our studies, U87B1-706A revealed a continuous increase in $\mathrm{O}_{2}{ }^{-}$and $\mathrm{H}_{2} \mathrm{O}_{2}$ contents from the tetrad stage to late uninucleate stage, which is the most vital stage of microspore abortion, with maximum values in the late uninucleate stage. Simultaneously, the ROS contents of U87B1-706A remained higher than those of 706B during the whole anther developmental course [38]. MDA, as the most common indicator of lipid peroxidation, is often associated with oxidative stress. Once formed, such high MDA can lead to cell damage through nucleic acid reactions with proteins, lipids and organelles [39]. The present study revealed that there is an obvious increase in MDA contents in U87B1-706A during the whole pollen developmental process, which were always higher than those in 706B along with the over-accumulation of ROS. The reason for the superfluous accumulation of $\mathrm{O}_{2}{ }^{-}, \mathrm{H}_{2} \mathrm{O}_{2}$ and MDA contents in male sterility could be related to the activities of antioxidative enzymes and nonenzymatic antioxidant components in response to the expression levels of relevant genes. Additionally, this result also indicates that the amplitude of dynamic ROS during all anther development stages is closely related to the occurrence and development of tapetum PCD. To better resist oxidative stress, plants form a high-efficiency antioxidant defensive system in the cell and thereby maintain the normal generation and clearance rates of ROS to reduce their effects on various biological molecules [40]. SOD, POD, CAT APX, and GPX are identified as key antioxidative enzymes that can eliminate redundant ROS [18]. Moreover, ASA and GSH as well as the antioxidative enzymes can constitute an ASA-GSH cycle system that effectively scavenges free radicals [41]. Our results showed SOD and POD activities in U87B1-706A were invariably higher than those in $706 \mathrm{~B}$ during the whole anther developmental process to defend against excess ROS accumulation. However, contrary to 706B, CAT, APX, GPX activities levels decreased in U87B1-706A at the late pollen development. Analogously, compared with 706B, the non-enzymatic antioxidant contents were always lower in U87B1-706A. It is possible that the excessive generation of ROS destroyed the normal antioxidant system, leading to a decrease in enzyme activity, thereby breaking the balance of the endogenous IAA pool. Many studies suggested that the over-accumulation of ROS can also affect the expression of various genes by oxidative damage [42,43]. Moreover, previous studies on the mitochondrial genome have revealed some genes or open reading frames (ORFs) are often chimeric and co-transcribed with genes that encode the mitochondrial subunits of the respiratory enzymes related to ROS release and further indicated that mutation and recombination have a direct relationship with CMS $[20,44,45]$. In our study, we performed RT-PCR to determine the expression levels of the genes encoding important antioxidant enzymes. The results showed the expression levels of the $S O D, C A T$ and $A P X$ genes were uniformly up-regulated during the early stages of pollen development in U87B1-706A, which were similar to the enzyme activity trends. It is possible that the disorganized transcript levels of enzymes genes are tightly linked to ROS generation, and ROS overproduction is not effectively eradicated by the antioxidative system, which result in the microspores chronically suffering from oxidative stress during anther development. In brief, we provide evidence supporting a vital role of the encoding of important antioxidant enzymes genes in dynamic tapetal ROS during the anther developmental stages.

\section{Methods}

\subsection{Plant Materials}

Cytoplasmic male sterile line, U87B1-706A containing Ae. uniaristata cytoplasm, and the maintainer line, 706B developed by Norwest A\&F University, which had the same nuclear background and which belonged to facultative wheat (Triticum aestivum L.) were used in our study. U87B1-706A was developed from a stable sterile line by backcrossing with 706B over 20 times [46]. All materials were planted conventionally at the Northwest A\&F University experimental farm in Yangling $\left(108^{\circ} \mathrm{E}, 34^{\circ} 15^{\prime} \mathrm{N}\right)$, 
China, during October 2014. All plants were arranged in randomized complete block designs with three replications. To identify the stability of sterility, U87B1-706A was checked by bagging in April 2015. The results demonstrated that the self-setting rate of U87B1-706A was zero, and thus the male sterility was complete and stable [6]. The dates of the microspore developmental stages were recorded for the sterile line U87B1-706A and the maintainer line 706B as described previously [31].

\subsection{Phenotypic Characterization}

According to the previous classification of microsporogenesis, we divided the overall anther development period into five stages: tetrad stage (Td), early uninucleate period (Eun), late uninucleate period (Lun), binucleate stage (Bn), and trinucleate stage (Tn) [47]. Photographs of anthers were obtained from the five microspore developmental stages using a stereomicroscope (Motic, K4000, Hong Kong, China). For scanning electron microscopy, anthers and microspores of trinucleate stage were dehydrated in a series of ethanol solutions, then dried, and observed by a scanning electron microscope (JSM-6360LV, JEOL, Tokyo, Japan) [48]. To identify the fertility of U87B1-706A and 706B, mature pollen grains from dehiscing anthers were stained using $\mathrm{I}_{2}-\mathrm{KI}$. In addition, we counted the $\mathrm{I}_{2}-\mathrm{KI}$ staining abortive ratio and the numbers of Ubisch bodies using IPP 6.0 software (Media Cybernetics, Rockville, MD, USA).

\subsection{Histological Analysis}

For observation of paraffin sections, anthers of different developmental stages were substituted by xylene and embedded in paraffin wax and cut into $8 \mu \mathrm{m}$ transverse sections and stained with $0.2 \%$ toluidine blue. For semithin sections as well as transmission electron microscopy observation, anthers were fixed, embedded, and stained as described by Zhang et al. [49]. The paraffin and semithin sections were photographed using a DS-U2 high resolution camera mounted on a microscope (Nikon, ECLIPSE, E600, Tokyo, Japan) and processed with NIS-Elements software (Nikon, Tokyo, Japan), and the ultrathin sections were observed and obtained with transmission electron microscope (Hitachi, H-7650, Tokyo, Japan) and an 832 charge-coupled device camera (Gatan, Abingdon, VA, USA). Then, we calculated the area of the tapetum cells in the section using CellSens Entry software (Olympus, Tokyo, Japan). The morphology and nuclear DNA of the microspores from various developmental stages were observed by stained with $1 \%$ acetocarmine and by staining the nuclei with DAPI.

\subsection{TUNEL and DNA Laddering Analysis}

For the TUNEL assay, paraffin sections were dehydrated and washed in a graded ethanol series, before incubating with $20 \mu \mathrm{mL}^{-1}$ Proteinase K (Roche, Basel, Switzerland) for $15 \mathrm{~min}$, and then washed in phosphate-buffered saline (PBS; $\mathrm{pH}=7.4$ ) for $15 \mathrm{~min}$. In situ nick-end labeling of nuclear DNA fragmentation was performed with the In Situ Cell Death Detection Kit, POD (Roche), following the manufacturer's instructions. Samples were analyzed with a fluorescence confocal scanner microscope (Nikon, Tokyo, Japan) using a 450/515 nm excitation/emission spectrum for TUNEL fluorescein and a 358/461 nm excitation/emission spectrum for DAPI as described in [15]. For DNA laddering analysis, total DNA was isolated from the anthers in different developmental stages [50]. Then, the total DNA was redissolved in Tris-EDTA (10 mmol L ${ }^{-1}$ Tris- $\mathrm{HCl}$ ( $\left.\mathrm{pH} 8.0\right), 5 \mathrm{mmol} \mathrm{L}^{-1}$ EDTA) and incubated at $37^{\circ} \mathrm{C}$ for $60 \mathrm{~min}$ in the presence of RNase A $\left(100 \mathrm{~g} \mathrm{~mL}^{-1}\right)$. Subsequently, $10 \mu \mathrm{g}$ of DNA was separated by electrophoresis on a $1.8 \%(w / v)$ TBE-agarose gel. The gel was then stained with ethidium bromide to visualize the DNA ladder [16]. 


\subsection{Quantification of ROS and Antioxidants}

Anthers $(1 \mathrm{~g})$ from each developmental stage were collected to determine the physiological indexes. The rate of superoxide anion $\left(\mathrm{O}_{2}{ }^{-}\right)$production, the $\mathrm{H}_{2} \mathrm{O}_{2}$ contents, and the MDA contents were measured according to Ba et al. [13]. The activities of antioxidative enzymes (SOD, POD, CAT, APX and GPX) were measured as described by Bibi et al. [51]. The AsA contents were calculated according to Jiang and Zhang [52]. The GSH contents were determined according to the method of Wang et al. [53]. All reactions were performed with three replications for each material from all developmental stages.

\subsection{Reverse Transcription-PCR (RT-PCR) and Quantitative Real-Time-PCR (qRT-PCR) Analysis of Antioxidant Enzyme Genes}

Total RNA was extracted using TRIZOL reagent (Tiangen, Beijing, China), and quantified spectrophotometrically by measuring absorbance at $260 \mathrm{~nm}$. Reverse transcription polymerase chain reaction (RT-PCR) and quantitative real-time-PCR (qRT-PCR) were used to study the expression of genes $(S O D, C A T, A P X)$. Primers used in this article were obtained from previously reported papers (Supplementary Table S1). For qRT-PCR, we used HiScript ${ }^{\mathrm{TM}}$ Q Select RT SuperMix for qPCR (Vazyme, Nanjing, China) to synthesize cDNA and we used AceQ ${ }^{\circledR}$ qPCR SYBR ${ }^{\circledR}$ Green Master Mix (Vazyme, China) to analyze qRT-PCR reaction products in ABI PRISM 7000 Sequence Detection System (Thermo Fisher, Waltham, MA, USA). For RT-PCR, the temperature profile was as follows: $95^{\circ} \mathrm{C}$ for $3 \mathrm{~min}$, followed by 35 cycles at $95^{\circ} \mathrm{C}$ for $30 \mathrm{~s}, 56^{\circ} \mathrm{C}$ for $30 \mathrm{~s}$, and $72{ }^{\circ} \mathrm{C}$ for $15 \mathrm{~s}$. All of the experiments were performed in triplicate.

\subsection{Statistical Analysis}

Statistical analyses were performed during different anther stages for each experiment $\left(\mathrm{I}_{2}-\mathrm{KI}\right.$ staining, counts of Ubisch bodies, area of the tapetum cells, determination of physiological indexes, and qRT-PCR) using one-way analysis of variance. Significant differences and correlation analysis were evaluated using SPSS statistical software (IBM, New York, NY, USA) and Excel Office (Microsoft Corporation, Washington, DC, USA). Data are the mean \pm SD of three biological replicates.

\section{Conclusions}

Based on cell biology, physiology, and molecular biology, we believe that excess ROS may be related to up-regulated transcript levels of $S O D, C A T, A P X$ genes, and may result in the destruction of the antioxidant system equilibration, thereby triggering the delayed tapetal PCD in U87B1-706A, which ultimately led to pollen abortion. These results provide a necessary theoretical basis for further study of the interaction between the ROS production system and tapetum transcription network in pollen abortion.

Supplementary Materials: Supplementary materials can be found at http:/ /www.mdpi.com/1422-0067/19/6/ $1708 / \mathrm{s} 1$.

Author Contributions: X.S. (Xiyue Song), Z.L., L.Z. and X.S. (Xiaoyi Shi) conceived and designed the study; Z.L. and S.L. performed the experiments; Z.L. wrote the article; G.H. provided technical assistance to Z.L.; X.S. (Xiyue Song) critically revised the manuscript. All of the authors read and approved the manuscript.

Funding: This study was sponsored by the National Natural Science Foundation of China $(31271792,31771874)$.

Acknowledgments: We thank Duncan E. Jackson for English editing of this article.

Conflicts of Interest: The authors declare no conflicts of interest. 


\section{Abbreviations}

$\begin{array}{ll}\text { CMS } & \text { cytoplasmic male sterility } \\ \text { PCD } & \text { programmed cell death } \\ \text { ROS } & \text { reactive oxygen species } \\ \text { SOD } & \text { superoxide dismutase } \\ \text { CAT } & \text { catalase } \\ \text { POD } & \text { peroxidase } \\ \text { APX } & \text { ascorbate peroxidase } \\ \text { GPX } & \text { glutathione peroxidase } \\ \text { ASA } & \text { ascorbic acid } \\ \text { GSH } & \text { glutathione } \\ \text { TUNEL } & \text { terminal deoxynucleotidyl transferase-mediated dUTP nick-end labeling } \\ \text { SEM } & \text { scanning electron microscopy } \\ \text { DAPI } & \text { 4',6-diamidino-2-phenylindole } \\ \text { TEM } & \text { transmission electron microscopy } \\ \text { MDA } & \text { malondialdehyde } \\ \text { Uby } & \text { Ubisch bodies } \\ \text { Ap } & \text { germination aperture } \\ \text { E } & \text { epidermis } \\ \text { En } & \text { endothecium } \\ \text { ML } & \text { middle layer } \\ \text { T } & \text { tapetum } \\ \text { Tds } & \text { tetrads } \\ \text { Msp } & \text { microspores } \\ \text { ER } & \text { endoplasmic reticulum } \\ \text { N } & \text { nucleus } \\ \text { Ta } & \text { tapetosome } \\ \text { V } & \text { vacuole } \\ \text { PE } & \text { primexine } \\ \text { Se } & \text { sexine } \\ \text { DM } & \text { deposit materials } \\ \text { PM } & \text { intine } \\ \text { In } & \\ & \end{array}$

\section{References}

1. Singh, S.P.; Srivastava, R.; Kumar, J. Male Sterility Systems in Wheat and Opportunities for Hybrid Wheat Development. Acta Physiol. Plant. 2015, 37, 1713. [CrossRef]

2. Gong, W.; Li, G.; Zhou, J.; Li, G.; Liu, C.; Huang, C.; Zhao, Z.; Yang, Z. Cytogenetic and Molecular Markers for Detecting Aegilops uniaristata Chromosomes in a Wheat Background. Genome 2014, 57, 489-497. [CrossRef] [PubMed]

3. Tsunewaki, K. Genome-plasmon Interactions in Wheat. Jpn. J. Genet. 1993, 68, 1-34. [CrossRef]

4. Gong, W.P.; Chu, X.S.; Han, R.; Wang, C.G.; Sun, Z.J.; Cheng, D.G.; Yu, X.C.; Liu, C.; Liu, J.J. Excellent Gene Exploration from Aegilops uniaristata Genome. Shandong Agric. Sci. 2015, 47, 11-15.

5. Song, X.Y.; Liu, S.D.; Zhu, L.C.; Hu, Y.G.; Xi, Y.J.; Ma, L.J.; Li, H.B.; He, P.R. The Comparative Study of the Cytoplasm Effect between Ae. Uniaristata and Ae. Kotschyi CMS Line. Acta Agric. Boreali-Occident. Sin. 1999, $8,48-52$.

6. Yao, M.; Ye, J.L.; Yang, Z.Q.; Duan, Y.; Meng, L.Y.; Yan, P.J.; Liu, Z.H.; Zhang, L.L.; Song, X.Y. Abortion Feature and Fertility Restoration of Five Kinds of Cytoplasmic Male Serile Wheat Lines. J. Triticeae Crops 2015, 35, 1676-1684.

7. Xie, H.T.; Wan, Z.Y.; Li, S.; Zhang, Y. Spatiotemporal Production of Reactive Oxygen Species by NADPH Oxidase Is Critical for Tapetal Programmed Cell Death and Pollen Development in Arabidopsis. Plant Cell 2014, 26, 2007-2023. [CrossRef] [PubMed] 
8. Falasca, G.; D'Angeli, S.; Biasi, R.; Fattorini, L.; Matteucci, M.; Canini, A.; Altamura, M.M. Tapetum and Middle Layer Control Male Fertility in Actinidia deliciosa. Ann. Bot. 2013, 112, 1045-1055. [CrossRef] [PubMed]

9. Flores-Renteria, L.; Orozco-Arroyo, G.; Cruz-Garcia, F.; Garcia-Campusano, F.; Alfaro, I.; Vazquez-Santana, S. Programmed Cell Death Promotes Male Sterility in the Functional Dioecious Opuntia Stenopetala (Cactaceae). Ann. Bot. 2013, 112, 789-800. [CrossRef] [PubMed]

10. Papini, A.; Mosti, S.; van Doorn, W.G. Classical Macroautophagy in Lobivia Rauschii (Cactaceae) and Possible Plastidial Autophagy in Tillandsia albida (Bromeliaceae) Tapetum Cells. Protoplasma 2014, 251, 719-725. [CrossRef] [PubMed]

11. Xu, Y.; Iacuone, S.; Li, S.F.; Parish, R.W. MYB80 Homologues in Arabidopsis, Cotton and Brassica: Regulation and Functional Conservation in Tapetal and Pollen Development. BMC Plant Biol. 2014, 14, 278. [CrossRef] [PubMed]

12. Yang, Y.; Dong, C.; Yu, J.; Shi, L.; Tong, C.; Li, Z.; Huang, J.; Liu, S. Cysteine Protease 51 (CP51), an Anther-specific Cysteine Protease Gene, is Essential for Pollen Exine Formation in Arabidopsis. Plant Cell Tissue Organ Cult. 2014, 119, 383-397. [CrossRef]

13. Ba, Q.S.; Zhang, G.S.; Wang, J.S.; Che, H.X.; Liu, H.Z.; Niu, N.; Ma, S.C.; Wang, J.W. Relationship between Metabolism of Reactive Oxygen Species and Chemically Induced Male Sterility in Wheat (Triticum aestivum L.). Can. J. Plant Sci. 2013, 93, 675-681. [CrossRef]

14. Yu, S.X.; Feng, Q.N.; Xie, H.T.; Li, S.; Zhang, Y. Reactive Oxygen Species Mediate Tapetal Programmed Cell Death in Tobacco and Tomato. BMC Plant Biol. 2017, 17, 76. [CrossRef] [PubMed]

15. Phan, H.A.; Iacuone, S.; Li, S.F.; Parish, R.W. The MYB80 Transcription Factor is Required for Pollen Development and the Regulation of Tapetal Programmed Cell Death in Arabidopsis thaliana. Plant Cell 2011, 23, 2209-2224. [CrossRef] [PubMed]

16. Wang, S.P.; Zhang, G.S.; Song, Q.L.; Zhang, Y.X.; Li, Y.; Chen, Z.; Niu, N.; Ma, S.C.; Wang, J.W. Programmed Cell Death, Antioxidant Response and Oxidative Stress in Wheat Flag Leaves Induced by Chemical Hybridization Agent SQ-1. J. Integr. Agric. 2016, 15, 76-86. [CrossRef]

17. Jimenez-Quesada, M.J.; Traverso, J.A.; Alche Jde, D. NADPH Oxidase-Dependent Superoxide Production in Plant Reproductive Tissues. Front. Plant Sci. 2016, 7, 359. [CrossRef] [PubMed]

18. Wan, C.; Li, S.; Wen, L.; Kong, J.; Wang, K.; Zhu, Y. Damage of Oxidative Stress on Mitochondria during Microspores Development in Honglian CMS line of rice. Plant Cell Rep. 2007, 26, 373-382. [CrossRef] [PubMed]

19. Mhadhbi, H.; Fotopoulos, V.; Mylona, P.V.; Jebara, M.; Aouani, M.E.; Polidoros, A.N. Alternative Oxidase 1 (Aox1) Gene Expression in Roots of Medicago Truncatula is a Genotype-specific Component of Salt Stress Tolerance. J. Plant Physiol. 2013, 170, 111-114. [CrossRef] [PubMed]

20. Panda, S.K.; Sahoo, L.; Katsuhara, M.; Matsumoto, H. Overexpression of Alternative Oxidase Gene Confers Aluminum Tolerance by Altering the Respiratory Capacity and the Response to Oxidative Stress in Tobacco Cells. Mol. Biotechnol. 2013, 54, 551-563. [CrossRef] [PubMed]

21. Bhoomika, K.; Pyngrope, S.; Dubey, R.S. Differential Responses of Antioxidant Enzymes to Aluminum Toxicity in Two Rice (Oryza sativa L.) Cultivars with Marked Presence and Elevated Activity of Fe SOD and Enhanced Activities of Mn SOD and Catalase in Aluminum Tolerant Cultivar. Plant Growth Regul. 2013, 71, 235-252. [CrossRef]

22. Li, J.; Dai, X.; Li, L.; Jiao, Z.; Huang, Q. Metabolism of Reactive Oxygen Species in Cytoplasmic Male Sterility of Rice by Marking Upmost Pulvinus Interval. Appl. Biochem. Biotechnol. 2015, 175, 1263-1269. [CrossRef] [PubMed]

23. Zhu, Y. Studies on Male Sterile Lines of Rice with Different Cytoplasms. Acta Agron. Sin. 1979, 5, $29-37$.

24. Sun, Z.; Tan, X.; Tao, G.; Guo, A.; Lei, W.; Zhu, G.; Zhao, Y.; Wang, C.; Cheng, C. Pollen Abortive Characteristics of Japonica CMS Lines with Different Cytoplasmic Sources. Hybrid Rice 2013, 28, 68-71.

25. Yi, J.; Moon, S.; Lee, Y.S.; Zhu, L.; Liang, W.; Zhang, D.; Jung, K.H.; An, G. Defective Tapetum Cell Death 1 (DTC1) Regulates ROS Levels by Binding to Metallothionein during Tapetum Degeneration. Plant Physiol. 2016, 170, 1611-1623. [CrossRef] [PubMed]

26. Zhou, Q.; Zhu, J.; Cui, Y.L.; Yang, Z.N. Ultrastructure Analysis Reveals Sporopollenin Deposition and Nexine Formation at Early Stage of Pollen Wall Development in Arabidopsis. Sci. Bull. 2015, 60, 273-276. [CrossRef] 
27. Rao, Y. Cytohistology of Cytoplasmic Male Sterile Lines in Hybrid Rice. In Hybrid Rice, Proceedings of the International Symposium on Hybrid Rice; Smith, W.H., Bostian, L.R., Cervantes, E.P., Eds.; International Rice Research Institute: Manila, Philippines, 1988; pp. 115-128.

28. Shi, Y.; Zhao, S.; Yao, J. Premature Tapetum Degeneration: A Major Cause of Abortive Pollen Development in Photoperiod Sensitive Genic Male Sterility in Rice. J. Integr. Plant Biol. 2009, 51, 774-781. [CrossRef] [PubMed]

29. Senatore, A.; Trobacher, C.P.; Greenwood, J.S. Ricinosomes Predict Programmed Cell Death Leading to Anther Dehiscence in Tomato. Plant Physiol. 2009, 149, 775-790. [CrossRef] [PubMed]

30. Min, L.; Zhu, L.; Tu, L.; Deng, F.; Yuan, D.; Zhang, X. Cotton GhCKI Disrupts Normal Male Reproduction by Delaying Tapetum Programmed Cell Death via Inactivating Starch Synthase. Plant J. 2013, 75, 823-835. [CrossRef] [PubMed]

31. Wang, S.; Zhang, G.; Song, Q.; Zhang, Y.; Li, Z.; Guo, J.; Niu, N.; Ma, S.; Wang, J. Abnormal Development of Tapetum and Microspores Induced by Chemical Hybridization Agent SQ-1 in Wheat. PLoS ONE 2015, 10, e0119557. [CrossRef] [PubMed]

32. Ji, J.J.; Huang, W.; Li, Z.; Chai, W.G.; Yin, Y.X.; Li, D.W.; Gong, Z.H. Tapetum-specific Expression of a Cytoplasmic orf507 Gene Causes Semi-male Sterility in Transgenic Peppers. Front. Plant Sci. 2015, 6, 272. [CrossRef] [PubMed]

33. Varnier, A.L.; Mazeyrat-Gourbeyre, F.; Sangwan, R.S.; Clement, C. Programmed Cell Death Progressively Models the Development of Anther Sporophytic Tissues from the Tapetum and is Triggered in Pollen Drains during Maturation. J. Struct. Biol. 2005, 152, 118-128. [CrossRef] [PubMed]

34. Zhang, D.S.; Liang, W.Q.; Yuan, Z.; Li, N.; Shi, J.; Wang, J.; Liu, Y.M.; Yu, W.J.; Zhang, D.B. Tapetum Degeneration Retardation is Critical for Aliphatic Metabolism and Gene Regulation during Rice Pollen Development. Mol. Plant 2008, 1, 599-610. [CrossRef] [PubMed]

35. Song, L.; Zhou, Z.; Tang, S.; Zhang, Z.; Xia, S.; Qin, M.; Li, B.; Wen, J.; Yi, B.; Shen, J.; et al. Ectopic Expression of BnaC.CP20.1 Results in Premature Tapetal Programmed Cell Death in Arabidopsis. Plant Cell Physiol. 2016, 57, 1972-1984. [CrossRef] [PubMed]

36. Zhang, D.; Liu, D.; Lv, X.; Wang, Y.; Xun, Z.; Liu, Z.; Li, F.; Lu, H. The Cysteine Protease CEP1, a Key Executor Involved in Tapetal Programmed Cell Death, Regulates Pollen Development in Arabidopsis. Plant Cell 2014, 26, 2939-2961. [CrossRef] [PubMed]

37. Semwal, V.K.; Singh, B.; Khanna-Chopra, R. Delayed Expression of SAGs Correlates with Longevity in CMS Wheat Plants Compared to Its Fertile Plants. Physiol. Mol. Biol. Plants 2014, 20, 191-199. [CrossRef] [PubMed]

38. Hameed, A.; Goher, M.; Iqbal, N. Drought Induced Programmed Cell Death and Associated Changes in Antioxidants, Proteases, and Lipid Peroxidation in Wheat Leaves. Biol. Plant. 2012, 57, 370-374. [CrossRef]

39. Deng, M.H.; Wen, J.F.; Huo, J.L.; Zhu, H.S.; Dai, X.Z.; Zhang, Z.Q.; Zhou, H.; Zou, X.X. Relationship of Metabolism of Reactive Oxygen Species with Cytoplasmic Male Sterility in Pepper (Capsicum annuum L.). Sci. Hortic. 2012, 134, 232-236. [CrossRef]

40. Sofo, A.; Scopa, A.; Nuzzaci, M.; Vitti, A. Ascorbate Peroxidase and Catalase Activities and Their Genetic Regulation in Plants Subjected to Drought and Salinity Stresses. Int. J. Mol. Sci. 2015, 16, 13561-13578. [CrossRef] [PubMed]

41. Kornyeyev, D. Effect of Chloroplastic Overproduction of Ascorbate Peroxidase on Photosynthesis and Photoprotection in Cotton Leaves Subjected to Low Temperature Photoinhibition. Plant Sci. 2003, 165, 1033-1041. [CrossRef]

42. Xie, Y.; Cui, W.; Yuan, X.; Shen, W.; Yang, Q. Heme Oxygenase-1 is Associated with Wheat Salinity Acclimation by Modulating Reactive Oxygen Species Homeostasis. J. Integr. Plant Biol. 2011, 53, 653-670. [CrossRef] [PubMed]

43. Awasthi, A.; Paul, P.; Kumar, S.; Verma, S.K.; Prasad, R.; Dhaliwal, H.S. Abnormal Endosperm Development Causes Female Sterility in Rice Insertional Mutant OsAPC6. Plant Sci. 2012, 183, 167-174. [CrossRef] [PubMed]

44. Wang, S.; Zhang, Y.; Song, Q.; Fang, Z.; Chen, Z.; Zhang, Y.; Zhang, L.; Zhang, L.; Niu, N.; Ma, S.; et al. Mitochondrial Dysfunction Causes Oxidative Stress and Tapetal Apoptosis in Chemical Hybridization Reagent-Induced Male Sterility in Wheat. Front. Plant Sci. 2017, 8, 2217. [CrossRef] [PubMed] 
45. Li, S.; Wan, C.; Hu, C.; Gao, F.; Huang, Q.; Wang, K.; Wang, T.; Zhu, Y. Mitochondrial Mutation Impairs Cytoplasmic Male Sterility Rice in Response to $\mathrm{H}_{2} \mathrm{O}_{2}$ Stress. Plant Sci. 2012, 195, 143-150. [CrossRef] [PubMed]

46. Zhu, L.; Hu, Y.; Ma, L.; Song, X.; Xi, Y.; Liu, S.; Yang, C.; He, P. A Comparasion of Wheat CMS Lines of Ae. Uniaristata and Ae. Kotschyi Cytoplasms. Acta Univ. Agric. Boreali-Occident. 1998, 26, 21-24.

47. Meng, L.; Liu, Z.; Zhang, L.; Hu, G.; Song, X. Cytological Characterization of a Thermo-sensitive Cytoplasmic Male-sterile Wheat Line Having K-type Cytoplasm of Aegilops kotschyi. Breed. Sci. 2016, 66, 752-761. [CrossRef] [PubMed]

48. Liu, M.; Li, H.; Su, Y.; Li, W.; Shi, C. G1/ELE Functions in the Development of Rice Lemmas in Addition to Determining Identities of Empty Glumes. Front. Plant Sci. 2016, 7, 1006. [CrossRef] [PubMed]

49. Zhang, L.Y.; Zhang, G.S.; Zhao, X.L.; Yang, S.L. Screening and Analysis of Proteins Interacting with TaPDK from Physiological Male Sterility Induced by CHA in Wheat. J. Integr. Agric. 2013, 12, 941-950. [CrossRef]

50. Hu, J.; Chen, G.; Zhang, H.; Qian, Q.; Ding, Y. Comparative Transcript Profiling of Alloplasmic Male-sterile Lines Revealed Altered Gene Expression Related to Pollen Development in Rice (Oryza sativa L.). BMC Plant Biol. 2016, 16, 175. [CrossRef] [PubMed]

51. Bibi, N.; Yuan, S.; Zhu, Y.; Wang, X. Improvements of Fertility Restoration in Cytoplasmic Male Sterile Cotton by Enhanced Expression of Glutathione S-Transferase (GST) Gene. J. Plant Growth Regul. 2013, 33, 420-429. [CrossRef]

52. Jiang, M.Y.; Zhang, J.H. Effect of Abscisic Acid on Active Oxygen Species, Antioxidative Defence System and Oxidative Damage in Leaves of Maize Seedlings. Plant Cell Physiol. 2001, 42, 1265-1273. [CrossRef] [PubMed]

53. Wang, H.H.; Feng, T.; Peng, X.X.; Yan, M.L.; Zhou, P.L.; Tang, X.K. Ameliorative Effects of Brassinosteroid on Excess Manganese-Induced Oxidative Stress in Zea mays L. Leaves. Agric. Sci. China 2009, 8, 1063-1074. [CrossRef]

(C) 2018 by the authors. Licensee MDPI, Basel, Switzerland. This article is an open access article distributed under the terms and conditions of the Creative Commons Attribution (CC BY) license (http:/ / creativecommons.org/licenses/by/4.0/). 